\title{
Towards developing a model to study alcohol drinking and craving in female mice housed in automated cages
}

\section{Koskela, Maryna}

2018-10-15

Koskela , M , Piepponen , T P , Andressoo , J-O , Võikar , V \& Airavaara , M 2018 , '

Towards developing a model to study alcohol drinking and craving in female mice housed in automated cages ' , Behavioural Brain Research , vol. 352 , pp. 116-124 . https://doi.org/10.1016/j.bbr.2018.03.027

http://hdl.handle.net/10138/305533

https://doi.org/10.1016/j.bbr.2018.03.027

cc_by_nc_nd

acceptedVersion

Downloaded from Helda, University of Helsinki institutional repository.

This is an electronic reprint of the original article.

This reprint may differ from the original in pagination and typographic detail.

Please cite the original version. 


\section{Accepted Manuscript}

Title: Towards developing a model to study alcohol drinking and craving in female mice housed in automated cages

Authors: Maryna Koskela, T. Petteri Piepponen, Jaan-Olle Andressoo, Vootele Võ ikar, Mikko Airavaara

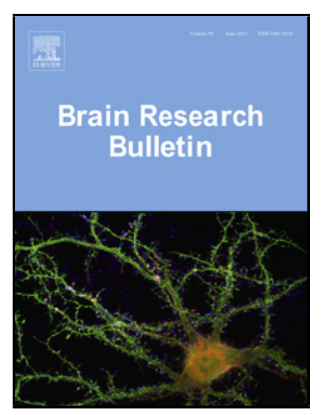

PII:

S0166-4328(17)31469-9

DOI: https://doi.org/10.1016/j.bbr.2018.03.027

Reference: BBR 11349

To appear in:

\section{Behavioural Brain Research}

Received date: $\quad 31-8-2017$

Revised date: 14-3-2018

Accepted date: $\quad$ 15-3-2018

Please cite this article as: Koskela M, Piepponen TP, Andressoo J-O, Võ ikar V, Airavaara M, Towards developing a model to study alcohol drinking and craving in female mice housed in automated cages, Behavioural Brain Research (2010), https://doi.org/10.1016/j.bbr.2018.03.027

This is a PDF file of an unedited manuscript that has been accepted for publication. As a service to our customers we are providing this early version of the manuscript. The manuscript will undergo copyediting, typesetting, and review of the resulting proof before it is published in its final form. Please note that during the production process errors may be discovered which could affect the content, and all legal disclaimers that apply to the journal pertain. 
Title: Towards developing a model to study alcohol drinking and craving in female mice housed in automated cages

\author{
of Helsinki, Helsinki, Finland \\ *Corresponding author: \\ Mikko Airavaara Ph.D. \\ Institute of Biotechnology \\ P.O. Box 56 (Viikinkaari 5D) \\ 00014 University of Helsinki, Finland \\ Cell: + 358504480944 \\ email: mikko.airavaara@ helsinki.fi
}

Maryna Koskela ${ }^{1}$, T. Petteri Piepponen ${ }^{3}$, Jaan-Olle Andressoo ${ }^{1}$, Vootele Võikar $^{2}$, Mikko Airavaara $^{1 *}$

${ }^{1}$ Institute of Biotechnology, P.O. Box 56, 00014 University of Helsinki, Finland

${ }^{2}$ Neuroscience Center, P.O. Box 56, 00014, University of Helsinki, Helsinki, Finland

${ }^{3}$ Division of Pharmacology and Pharmacotherapy, Faculty of Pharmacy, P.O. Box 56, 00014, University

\title{
Highlights
}

- Animal studies in automated cages and with group housing provide a way to study behavior without human interaction

- Intermittent alcohol drinking in automated cages led to increased number of nosepokes (craving measure) on withdrawal day one and day ten.

\begin{abstract}
It is about half a century ago when the so-called "Wise model" to study alcohol drinking behavior in rats was established. The model was based on voluntary intermittent access to increasing concentrations of alcohol. We aimed to establish a model of alcohol craving and used an extinction test on withdrawal days 1 and 10 to study motivation for alcohol. For this purpose, the alcohol drinking training was paired with light cues to establish conditioning. The extinction test was carried out without alcohol but in the presence of light cues and empty bottles. The outcome measures were number of visits, nosepokes, and licks in the conditioned corner where the number of nosepokes represents how much mice "want" alcohol and number of licks shows how much mice "like" alcohol. The number of nosepokes during withdrawal is a measure of craving. Late withdrawal craving was found when intermittent alcohol access was carried out in the automated cages. In this case, we observed a significant increase in the number of nosepokes on both withdrawal days 1 and 10 as compared to water control. The number of nosepokes in the withdrawal days did not correlate with alcohol dose, but number of nosepokes on withdrawal day 1 correlated with the number of nosepokes on the last training day. Although we did not observe incubation of alcohol craving after withdrawal, the craving was increased at the late time point. We conclude that we have established a new tool to study alcohol drinking behavior and craving in female mice.
\end{abstract}

Key words: alcohol addiction, IntelliCage, intermittent alcohol access, craving, conditional stimuli, social interaction.

\section{Introduction}


Drug addiction is a complex brain disorder that progresses from impulsive to compulsive drug use resulting in chronic and relapsing drug taking [1]. The development of alcohol dependence can be divided into a five-stage cycle: intoxication (binge), compulsive drinking, withdrawal, craving, and relapse. Relapse to alcohol use can occur after a long withdrawal period in humans [2]. It has been suggested that craving has a major role in relapse [3] and it is one of the key elements in alcohol dependence [4]. Craving can be triggered by a drug-associated (conditioned) stimuli, in other words, it is cue-induced. Moreover, relapse can be induced with drug-associated cues by provoking craving [5].

Animal models in alcohol addiction research provide the possibility to study mechanisms underlying disease progression [6]. Common animal models in alcohol dependence research were developed based on different procedures such as conditioned place preference, free-choice bottle and, the most widely used, operant self-administration [7]. The voluntary intermittent access to ethanol, originally established by Wise [8] and revised in work by Simms and colleagues [9], has become a commonly used approach to model alcohol consumption in rodents [6]. In the intermittent-access model, there are episodes of continuous alcohol access and deprivation that alternate for short time periods. Notably, most of the existing models share common limitations. First, animals are single-housed, although such isolation can be stressful in social species $[10,11]$. Second, animal handling has been reported to produce major variability between experiments [12]. Some groups have described models of alcohol drinking behavior in the automated home cage environment under different settings [13, 14]. One of the most important advantages of using automated cages is it allows monitoring of individual animals in a social context and without animal handling $[15,16]$. The advantage is to measure goal-derived behavior in a conditioning paradigm where a nosepoke can lead to a light cue [16]. However, there are no studies published so far where alcohol craving has been measured in a social context in rodents.

Here, we set out to study whether the intermittent voluntary ethanol drinking can be adopted in automated cages in a social context, and whether this model can be used to study cue-associated alcohol craving in female C57BL/6JRccHsd mice. In our experiments, we have employed the model of voluntary intermittent access to gradually increasing the concentration of ethanol in two different ways.

\section{Material and Methods}

\subsection{Ethics statement}


The animal experiments were performed according to the EU legislation harmonized with Finnish legislation and have been approved by the National Animal Experiment board of Finland (ESAVI/198/04.10.07/2014, ESAVI/7812/04.10.07/2015).

\subsection{Experimental Animals}

The behavioral experiments were performed in female C57BL/6JRccHsd mice ( $\mathrm{n}=65$, Envigo). The mice arrived at the age of 8 weeks old and were housed under temperature-controlled conditions at $20-22^{\circ} \mathrm{C}$ in $12 \mathrm{~h}$ light/dark cycle with lights on at $06.00 \mathrm{am}, 5-11$ animals per cage (depends on the size of the cage) with ad libitum access to standard lab chow and water. The mice were individually recognized by RFID-transponders (Planet ID GmbH, Germany) that were implanted under the skin one week before experiments began. The animals were 10 weeks old, average $19 \mathrm{~g}$ of weight and grouped 8-11 mice per cage (standard home cage or IntelliCage) at the beginning of the experiments.

\subsection{Automated home cage analysis}

Behavior was analyzed using the IntelliCage system (TSE, Bad Homburg, Germany) [15, 17]. The apparatus allows performing tests without handling the mice under fully automated conditions in the home cage environment. All corners of the cages have an antenna that reads RFID signals. The cages were controlled by a computer with dedicated software (IntelliCage Plus), executing pre-programmed experimental schedules. The following behavioral parameters were recorded: number of visits to the corner, number of nosepokes to the door, and number of licks. The nosepoke measure represents how much mice "want" to get alcohol while the number of licks shows how much mice "like" alcohol. The schematic representation of the cages is shown in Fig. 1A and reviewed in [15]. Green light was used as a conditional stimulus (CS+ side). The bottle with alcohol is placed in the $\mathrm{CS}+$ side for the alcohol group of mice (Fig. 1B). Four triangular red shelters (Tecniplast, Buguggiate, Italy) were placed in the middle of the cages. They were used as sleeping quarters and as a stand to reach the food. The floor was covered with a layer of bedding.

\subsection{Behavioral procedures}


The intermittent schedules of ethanol access was adapted from R. A. Wise's studies [8]. The intermittent alcohol access procedures were done in two different settings.

i) Intermittent alcohol access procedure in the automated cages (Procedure I): The experimental timeline is outlined in Fig. 1C. 31 mice total (10 for water group and 21 for intermittent alcohol group) were used in this experiment. The animals were combined in groups of 10 and 11 mice per cage for the intermittent alcohol group and 10 mice per cage for the water group. The mice were placed in the automated cages where they spent the first week for a habituation period that consisted of free adaptation phase ( 3 days, all doors in all corners were open, animals could enter and drink water in any corner) and nosepoke adaptation phase (4 days, all doors in all corners were closed, nosepoke opened the door for 7 seconds). Thereafter, two corners were assigned for each animal. Half of the mice had access to corners I\&II and another half to corners III\&IV. During the training, two sides of the cage corner (one with alcohol and one with water) are available for mice and the side with alcohol is signaled by a green light (conditional stimulus, $\mathrm{CS}+$ ). Nosepoke to this side opens the door for $7 \mathrm{sec}$ and switches on green LED light until the end of drinking. Nosepoke to another side of the corner opens door for water (CS-). On days when alcohol was replaced by water there was no conditional stimulus (green light) on the side. The mice were given free choice between ethanol solutions and water on every other day for 16 days of acclimation period. The bottles were switched every day between $10.00 \mathrm{am}$ and $11.00 \mathrm{am}$. The mice were first given exposure to $4 \%(\mathrm{v} / \mathrm{v})$ ethanol solution. On each following day of ethanol exposure the concentration of the solutions was raised by $1 \%$ until $12 \%$ ethanol solution was reached. After this point the mice began the training period of the experiment, where they had a choice between $12 \%$ ethanol and water every day for 14 days. The control water group (constitutive) had the same schedule for green light as the intermittent alcohol group except water bottles were in both sides (conditional and non-conditional) during the whole training period.

ii) Intermittent alcohol access procedure in the standard home cage (Procedure II): The experimental timeline is outlined in Fig 1D. 38 mice total (10 for water, 14 for control alcohol and 14 for intermittent alcohol) were used in this experiment. The mice were grouped in seven animals per cage for control alcohol and intermittent alcohol groups and ten animals per cage for water group throughout the experiment. The intermittent alcohol group of mice spent the 
acclimation period in standard home cages where they were given a free choice between ethanol solutions and water on every other day for 31 days of the acclimation period. The bottles were switched every day between $10.00 \mathrm{am}$, and $11.00 \mathrm{am}$. The mice were first given exposure to $4 \%(\mathrm{v} / \mathrm{v})$ ethanol solution. On each day following ethanol exposure, the concentration of the solutions was raised by $1 \%$, until $12 \%$ ethanol solution was reached. After this point, the intermittent alcohol group had a choice between $12 \%$ ethanol and water every day for the next 14 days. All mice had access to water at all times. The control alcohol group had just water during this period. After the acclimation period, all groups were placed in the automated cages. To make sure mice were able to access fluids, the mice spent two days of habituation period ( 1 day of free adaptation and 1 day of nosepoke adaptation). During these two days, only water was available in corners. After that, both control alcohol and intermittent alcohol groups had a training period for 10 days with similar settings described in section 2.4.1. The control water group had the same schedule for green light as both alcohol groups except water bottles were in all sides (conditional CS+ and non-conditional CS-) at all times.

\subsubsection{Alcohol withdrawal phase.}

After the training period, the mice were removed from the automated cages to their standard home cages. For the extinction tests, the mice were brought to the automated cages and after each test returned to the standard home cages.

\subsubsection{Extinction tests in automated cages.}

Extinction tests were performed 1 and 10 days after the end of training between $10.00 \mathrm{am}$, and $11.00 \mathrm{am}$. During the probe trials $(1 \mathrm{~h})$ experimental design was similar to training except there was no liquid in the bottles.

\subsection{Statistical analysis}


The extracted data were analyzed using SPSS. The parametric repeated measures or two- or three-way ANOVA were used and statistically significant effects $(\mathrm{P}<0.05)$ were followed by post hoc tests. As post hoc test we used Bonferroni test. . All means are presented with their standard errors $( \pm \mathrm{SEM})$.

\section{Results}

\section{Intermittent access to alcohol in the automated cage}

Initially, we assessed behavioral activity in mice that had intermittent access to gradually increasing concentrations of alcohol in the automated cages (procedure I, Fig. 1C). As described above, each mouse received alcohol or water in two of the corners in the cages with $\mathrm{CS}+$. We first analyzed the withinsubjects effects and whether there are changes in the number of visits in the conditioned corner during the training. There was a significant day effect indicating that the number of visits was different during different training days (Fig. 2A, Day Effect $\mathrm{F}_{(20,580)}=9.8, \mathrm{p}<0.001$ ). Moreover, the within-subjects effects showed a tendency for Day $\times$ Training Drug interaction $\left(\mathrm{F}_{(20,580)}=1.3, \mathrm{p}=0.15\right)$ also indicating that the number of visits differs during the training. The between-subjects analysis showed that there is no difference in the number of visits in the conditioned corner between alcohol and water groups $\left(\mathrm{F}_{(1,29)}\right.$ $=2.35, \mathrm{p}=0.136)$.

We then analyzed the number of nosepokes in the CS+ and CS- sides of the conditioned corners. The within-subjects effects analysis showed a significant training day effect on the CS+ side (Fig. 2B, $\mathrm{F}_{(20 \text {, }}$ $580)=4.8, \mathrm{p}<0.001)$ indicating number of nosepokes changes during the training. There was no Day $\times$ Training Drug interaction $\left(\mathrm{F}_{(20,580)}=1.1, \mathrm{p}=0.38\right)$. However, the between-subjects analysis revealed a significant Training Drug effect in the $C S+$ side of the corner $\left(F_{(1,29)}=6.9, p=0.014\right)$, showing that the numbers of nosepokes were higher in the alcohol group than in the water group. Similar results were seen for number of nosepokes in the CS- side, and there was a significant training day effect in the withinsubjects effects analysis (Fig. $2 \mathrm{C}, \mathrm{F}_{(20,58)}=14.3$, p<0.001). The between-subjects analysis showed no significant Training Drug effect $\left(\mathrm{F}_{(1,29)}=3.0, \mathrm{p}=0.09\right)$ in the CS- indicating that both alcohol and water groups perform similarly in the non-cued side. 
Next, we analyzed the number of licks in the CS+ and CS- sides of the conditioned corners. The withinsubjects effects analysis showed a significant training day effect in the CS+ side as well Day $\times$ Training Drug interaction (Fig. 2D, $\mathrm{F}_{(20,580)}=15.2, \mathrm{p}<0.001 ; \mathrm{F}_{(20,580)}=2.3, \mathrm{p}=0.001$ respectively) showing that the number of licks is different at different days of training. However, the between-subjects analysis did not show significant Training Drug effect in the $C S+$ side of the corner $\left(\mathrm{F}_{(1,29)}=1.7, \mathrm{p}=0.209\right)$ indicating that both alcohol and water groups perform a similar number of licks. Similar results were found in the CS- side Fig. 2E, training day effect $\left(\mathrm{F}_{(20,580)}=17.62\right.$, $\mathrm{p}<0.001$; Day $\times$ Training Drug interaction $\mathrm{F}_{(20,580)}$ $=3.0, \mathrm{p}<0.001$, between-subjects Training Drug effect $\left.\mathrm{F}_{(1,29)}=0.80, \mathrm{p}=0.39\right)$. We then analyzed the effects between $\mathrm{CS}+$ and CS- sides and found a significant Training day $\times$ CS side interaction $\left(\mathrm{F}_{(20,1160)}\right.$ $=31.0, \mathrm{p}<0.001$ and Training day $\times$ Training Drug $\times C S$ side interaction $\left.F^{20,1160}=4.3, p<0.001\right)$ showing that time-course on licks is drastically different in the $\mathrm{CS}+$ and - side. In the CS+ side the number of licks is decreasing, and in the CS- side it is increasing during the training.

Next, we analyzed the visit duration in the conditioned corners. We found that the alcohol group spent more time during training in the corner with the light cue associated with alcohol drinking than the water group (Fig. 3A, within subjects Day: $\mathrm{F}_{(20,580)}=1.3$, $\mathrm{p}=0.2$ Day $\times$ Training Drug interaction: $\mathrm{F}_{(20,580)}=$ 0.8, $\mathrm{p}=0.7$; respectively; between-subjects Training Drug: $\left(\mathrm{F}_{(1,29)}=65.0, \mathrm{p}<0.0001\right)$.

We then estimated consumed alcohol dose. It has been estimated that a single lick on a bottle corresponds to the consumption of $3 \mu \mathrm{l}$ of liquid [14]. Thus, multiplying the number of performed licks with $3 \mu 1$, we calculated the total volume of consumed liquid. The calculation of consumed ethanol volume was performed by the formula: Ethanol, $\mathrm{ml}=$ Total volume of consumed liquid, $\mathrm{ml}^{*}$ Ethanol $\% / 100 \%$. The weight of consumed ethanol we calculated by the formula: Ethanol, $\mathrm{g}=$ Ethanol, $\mathrm{ml} * 0.79 \mathrm{~g} / \mathrm{ml}$, where $0.79 \mathrm{~g} / \mathrm{ml}$ is ethanol density. The alcohol dose was determined by the formula: Alcohol dose $\mathrm{g} / \mathrm{kg}=$ Ethanol, g/ Animal weight, kg. The weight of animals was taken every week. Thus, we have found that ethanol dose started from $5.2 \pm 0.3 \mathrm{~g} / \mathrm{kg}$ and peaked at $17.1 \pm 2.0 \mathrm{~g} / \mathrm{kg}$ on the first day that $12 \%$ alcohol was given (Fig. 3B). After that when 12\% alcohol was given continuously the consumed amount decreased to $9.7 \pm 1.3 \mathrm{~g} / \mathrm{kg}$. 


\section{Extinction tests after intermittent access to alcohol}

After training, the mice were brought back to their standard home cages and the cue-induced extinction tests were carried out on days 1 and 10 after withdrawal in the automated cages for $1 \mathrm{~h}$. We first analyzed the number of visits in the conditioned corners. The within-subjects effect analysis showed that there was a significant Day effect (Fig. 4A, $\mathrm{F}_{(1,28)}=4.7, \mathrm{p}=0.03$ ) and the between-subjects effects analysis showed a significant Training drug effect $\left(\mathrm{F}_{(1,28)}=4.5, \mathrm{p}=0.043\right)$. However, the post-hoc comparisons did not show any differences between training drugs or between days of each training drug.

We then analyzed the number of nosepokes (a measure of craving after withdrawal) in CS+ and CSsides on withdrawal days 1 (WD1) and 10 (WD10). The within-subjects effects showed significant day effects $\left(\mathrm{F}_{(1,56)}=11.5, \mathrm{p}=0.001\right)$ and the between-subjects effects showed a significant Training Drug effect $\left(\mathrm{F}_{(1,56)}=11.2, \mathrm{p}=0.001\right)$, indicating that the number of nosepokes in the alcohol group is higher compared to the water group. No significant effects were found in the Day effect $\times$ Training Drug effect interaction $\left(\mathrm{F}_{(1,56)}=0.07, \mathrm{p}=0.79\right)$ or Day effect $\times$ CS-side effect $\left.\mathrm{F}_{(1,56)}=0.46, \mathrm{p}=0.5\right)$. Three-way ANOVA Day $\times$ Training Drug $\times$ CS-side effect did not show a significant difference $(\mathrm{p}=0.5)$. The post hoc comparisons showed that the alcohol group performed a significantly higher number of nosepokes on day 10 in the CS+ side than the water group ( $\mathrm{p}=0.46$, , Bonferroni test). No statistically significant differences were found in the in the CS+ side on day 1 or in the CS- side.

The within-subjects effects for the CS+ and CS- licks showed a significant Day effect $\left(F_{(1,56)}=34.7\right.$, $\mathrm{p}<0.001)$ and also the between-subjects effects showed a significant Training Drug effect $\left(\mathrm{F}_{(1,56)}=6.7\right.$, $\mathrm{p}=0.012)$. Day effect $\times$ Training Drug effect interaction $\left(\mathrm{F}_{(1,56)}=3.6, \mathrm{p}=0.06\right)$ or Day effect $\times$ CS-side effect $\left.\mathrm{F}_{(1,56)}=0.20, \mathrm{p}=0.65\right)$ did not show significant effects. Three-way ANOVA Day $\times$ Training Drug $\times$ CS-side did not show the difference $(\mathrm{p}=0.5)$. The post hoc comparisons showed no significant differences between water and alcohol groups on withdrawal days 1 and 10 in the CS+ side, but there was a highly significant decrease in the number of licks from day 1 to day 10 in both groups $(\mathrm{P}<0.001$, Bonferroni test). Similar differences were found in the CS- side.

Additionally, the within-subjects effects for time spent in conditioned corners revealed a significant Day effect (Fig. 4D, $\mathrm{F}_{(1,29)}=15.7, \mathrm{p}<0.001$ ) showing that during extinction, time spent in the conditioned 
corner decreases. The between-subjects effects revealed a significant Training Drug effect $\left(\mathrm{F}_{(1,29)}=12.2\right.$, $\mathrm{p}=0.002$ ) showing that the alcohol group spent more time in the conditioned corner than the water group. Furthermore, Bonferroni post hoc test showed a significant difference on withdrawal day $1(\mathrm{p}=0.037)$, but not on day $10(\mathrm{p}=0.212)$ between water and alcohol groups.

\section{Intermittent alcohol access procedure in the standard home cage.}

Next, we wanted to study whether we can observe similar alcohol drinking behavior and craving with shorter cue-associated access to alcohol. We performed the same procedure with intermittent access to increasing concentrations of alcohol in standard home cages followed by training in the automated cages for 10 days (Fig. 1D). During the training in the automated cages, there was $12 \%$ alcohol available every day. We also had a group of mice that went directly for training in the automated cages without acclimation period with intermittent access to increasing concentrations of alcohol. The experimental timeline is presented in Fig. 1D, and details are described in the Material and Methods section.

We first analyzed the number of visits in the conditioned corner during training for within-subjects effects. There was a significant day effect showing that the number of visits was different during training (Fig. 5 A, Day Effect $\left.\mathrm{F}_{(9,315)}=7.7, \mathrm{p}<0.001\right)$. Also, there was a significant Day $\times$ Training Drug interaction $\left(\mathrm{F}_{(18,315)}=3.0, \mathrm{p}<0.001\right)$. The between-subjects analysis did not show a significant effect for the Training Drug for visits in the $\mathrm{CS}+\operatorname{corner}\left(\mathrm{F}_{(2,35)}=1.3, \mathrm{p}=0.27\right)$.

The analysis for the number of nosepokes in the CS+ side showed a significant effect in the withinsubjects for the Day effect (Fig. 5B, Day effect $\mathrm{F}_{(9,315)}=3.1, \mathrm{p}=0.001$ ), and for Day $\times$ Training Drug interaction $\left(\mathrm{F}_{(18,315)}=3.6, \mathrm{p}<0.001\right)$. The between-subjects analysis did not show a significant effect on the Training Drug in the $\mathrm{CS}+$ side of the corner $\left(\mathrm{F}_{(2,35)}=2.8, \mathrm{p}=0.07\right)$. These results indicate that there are differences in the number of nosepokes between training days, but between different groups there are no differences. The analysis of nosepokes in the CS- side showed a significant Day effect and Day $\times$ Training drug interaction (Fig. $5 \mathrm{C}, \mathrm{F}_{(9,315)}=19.6, \mathrm{p}<0.001 ; \mathrm{F}_{(18,315)}=2.3, \mathrm{p}=0.002$, respectfully). Also, the between-subjects analysis showed a significant Training Drug effect $\left(\mathrm{F}_{(2,35)}=9.8, \mathrm{p}<0.001\right)$. These 
results indicate that both alcohol groups perform more nosepokes in the CS- side to receive water than the water group.

The analysis for the number of licks in the CS+ side showed a significant effect in the within-subjects for the Day effect $\left(\right.$ Fig. 5D, $\mathrm{F}_{(9,315)}=3.2$, $\left.\mathrm{p}=0.001\right)$, and for Day $\times$ Training Drug interaction $\left(\mathrm{F}_{(18,315)}=\right.$ 1.9, $\mathrm{p}=0.01$ ). The between-subjects analysis did not show a significant effect of the Training Drug in the $\mathrm{CS}+$ side of the corner $\left(\mathrm{F}_{(2,35)}=1.7, \mathrm{p}=0.20\right)$. These results indicate that there is a difference in the number of licks between days, and even when the training drug is taken into account, there is no overall effect between groups. The analysis of licks in the CS- side showed a significant Day effect and Day $\times$ Training drug interaction (Fig. 5E, $\mathrm{F}_{(9,315)}=10.6$, $\mathrm{p}<0.001 ; \mathrm{F}_{(18,315)}=1.8, \mathrm{p}=0.03$, respectively). The betweensubjects analysis showed a significant Training Drug effect $\left(\mathrm{F}_{(2,35)}=19.9, \mathrm{p}<0.001\right)$. These results indicate that both alcohol groups perform more licks in the CS- side to receive water than the water group, and are in line with the nosepoke data.

We then compared the alcohol intake between the two groups. In both groups, the ethanol dose increased during the 10-day period (Fig. 6). In the intermittent access to alcohol (procedure II) group, ethanol dose started from 3.0 and ended at $7.2 \mathrm{~g} / \mathrm{kg}$, and the alcohol control group started from 2.3 and ended at 4.6 $\mathrm{g} / \mathrm{kg}$. The statistical analysis showed a significant Day effect $\left(\mathrm{F}_{(9,225)}=5.6, \mathrm{p}=0.002\right)$ but no Day $\times$ Training drug effect $\left(\mathrm{F}_{(9,225)}=0.9, \mathrm{p}=0.27\right)$ in the within-subjects analysis. The between-subject effects also showed no Training drug effects $\left(\mathrm{F}_{(1,25)}=0.7, \mathrm{p}=0.40\right)$.

\section{Extinction tests after 10-d training in the automated cage with procedure II.}

Similarly as above, the mice were brought back to their standard home cages after training and cueinduced extinction tests were carried out on day 1 and 10 after withdrawal in the automated cages for $1 \mathrm{~h}$. The within-subjects effect analysis for visits showed that there was a significant Day effect (Fig. 7A, F(1, $35)=67.8, \mathrm{p}<0.001)$ but no Day $\times$ Training Drug interaction $\left(\mathrm{F}_{(2,35)}=1.6, \mathrm{p}=0.22\right.$. The between-subjects effects analysis did not show a significant Training drug effect $\left(\mathrm{F}_{(2,35)}=1.3, \mathrm{p}=0.28\right)$. 
We then analyzed the number of nosepokes (craving measure) in CS+ and CS- sides on withdrawal days 1 and 10. The within-subjects effects showed a significant day effect $\left(\mathrm{F}_{(1,69)}=2.6, \mathrm{p}=0.11\right)$ and Day $\times$ Training Drug interaction $\left(\mathrm{F}_{(2,69)}=3.7, \mathrm{p}=0.03\right)$ and no Day $\times$ Training Drug $\times$ CS interaction $\left(\mathrm{F}_{(2,69)}=\right.$ 0.08, $\mathrm{p}=0.93$ ). Three-way ANOVA Day $\times$ Training Drug interaction $\times$ CS interaction was not significant $\left(\mathrm{F}_{(2,69)}=0.08, \mathrm{p}=0.96\right)$. The between-subjects effects showed a significant Training Drug effect $\left(\mathrm{F}_{(2,69)}=\right.$ 4.7, $\mathrm{p}=0.012$ ), indicating that the number of nosepokes between groups is different. However, post hoc comparisons did not show any significant differences between groups on days 1 and 10 in either CS+ or CS- sides.

The within-subjects effects for the CS+ and CS- licks showed a significant Day effect $\left(\mathrm{F}_{(1,69)}=15.2\right.$, $\mathrm{p}<0.001)$ but no Day $\times$ Treatment interaction $(\mathrm{p}=0.08)$ nor Day $\times$ Training Drug $\times$ CS interaction $(\mathrm{p}=0.25)$. Three-way ANOVA Day $\times$ Training Drug interaction $\times$ CS interaction was not significant $\left(\mathrm{F}_{(2,}\right.$ $\left.\left.{ }_{69}\right)=1.4, \mathrm{p}=0.25\right)$. The between-subjects effects showed a significant Day effect $\left(\mathrm{F}_{(1,69)}=15.2, \mathrm{p}<0.001\right)$ and Day $\times$ CS interaction $\left(\mathrm{F}_{(1,69)}=5.3, \mathrm{p}=0.02\right)$, but no Day $\times$ training Drug interaction $(\mathrm{p}=0.08)$.

Additionally, we found a significant day effect on time spent in the conditioned corner, but all groups had decreased time spent on withdrawal day 10 (Day effect: $F_{(1,35)}=82$, $p<0.001$; Day $\times$ Training drug interaction $\mathrm{p}=0.3$ ). However, there was a significant between-subjects effect, in the conditioned corner on day $1\left(\mathrm{~F}_{(1,35)}=3.4, \mathrm{p}<0.05\right)$, but post hoc comparison did not show any differences.

\section{Pearson Correlation coefficient}

We next examined whether the number of nosepokes in the extinction tests after intermittent access to alcohol in the automated cages correlates with the number of nosepokes on the last day of training or to the amount of alcohol used. The Pearson correlation coefficient was analyzed for the number of nosepokes on WD1 and WD10. The alcohol dose $(\mathrm{g} / \mathrm{kg} / 24 \mathrm{~h})$ on the last day of training did not correlate with the number of nosepokes on WD1 (Fig. 8A, r = -0.22, p=0.34) or WD10 (Fig, 8B, r =0.11, p = 0.64). The number of nosepokes on the last training day correlated with the number of nosepokes on WD1 (Fig. 8C, r =0.53, p=0.01) but not with the number of nosepokes on WD10 (Fig. 8D, $r=0.25, p=$ 0.27). 


\section{Discussion}

Over decades, researchers in the addiction field have developed a number of animal models to gain neurobiological insights into the development of addiction. Many determinants that can affect experimental outcomes have to be considered, one of which is social exclusion [18]. Thus, most models that have been used are set for single-housed animals. In case of rodents, such isolation is a stressful factor, and stress can lead to increased alcohol consumption [19]. Another limitation that the singlehoused animal model can face is handling by the researcher that produces experimental variations [12, 20]. A recent study has shown that single-housed mice consume more alcohol in comparison with grouphoused animals [21]. However, in this study mice were given $20 \%$ ethanol without preliminary alcohol habituation. In contrast, Smutek and colleagues provided evidence that group-housed mice in an automated cage under intermittent access to alcohol are motivated to drink alcohol despite the risk of punishment [14].

In the present study, we aimed to determine whether housing mice in a social context in the automated cages with increasing alcohol concentrations led to increased craving after withdrawal. We found that when the long-term conditioning is implemented there is increased craving (number of nosepokes) only on withdrawal day 10. However, when the mice adapted to alcohol drinking first in the home cages with intermittently increasing concentrations followed by housing in automated cages with conditioning, this did not lead to similar craving on withdrawal day 10. Moreover, we observed that nosepokes in the withdrawal days did not correlate with the alcohol dose the mice drank. Our results suggest that cue induction is not related to the amount of alcohol being consumed but rather related to the number of conditioned cues together with the alcohol drinking. This is further supported by the findings from procedure II, where we foud that mice had similar behavior in training and withdrawal phase despite whether they had experienced alcohol drinking before placing them into automated cages or not.

Our work was inspired by studies on incubation of craving after withdrawal [3]. In animal drug abuse studies it has been shown that cue-induced craving after withdrawal increases over time, and for cocaine, craving is high for extended periods of time [22]. A similar phenomenon has been observed for heroin [23], methamphetamine [24], nicotine [25], sucrose [26] and for alcohol [27]. In this study, we did not observe incubation of craving for alcohol. However, we found an increased cue-induced number of 
nosepokes (craving measure) at the later time point. Interestingly, the number of nosepokes on withdrawal day 1 correlated with the number of nosepokes on the last training day, but the number of nosepokes on withdrawal day 10 did not correlate with the number of nosepokes on the last training day. Indeed, the extinction behavior was at a similar level on withdrawal days 1 and 10, and therefore it is likely that there is no suppression of cue-responding in early withdrawal that has been previously discussed for incubation of craving [3]. The increased craving that was indicated by the number of nosepokes was found in the model with more cue-induced pairings, and where the alcohol drinking started intermittently with increasing concentrations in the automated cages. Interestingly, the time spent in the conditioned corner was increased only in the early withdrawal time point. The additive value of this new model is the implementation of social context and carrying out experiments without human handling that can cause experimental variations.

Since an incubation effect was not observed, this could be due to differences in the context as compered to the classical operant conditioning chamber used in self-administration studies. In our case, we have the water available in the conditioned corner, and although there is no cue association with it, this can be a confounding factor and an external extinction factor. Moreover, in procedure I on water only days the conditioned corner is available, and there is no cue related to either side of the corner, and this can also be the case when mice undergo extinction learning during the training. Additionally, more robust conditioned behaviors could be observed if there would be just one spout available in one corner during training that would be assigned either to water or alcohol. In future studies, it would be important to have in the conditioned corner only the alcohol and cued side available and to have the water only corners for non-conditioned.

In this study, we performed extinction tests on both withdrawal days 1 and 10 and did not have a group of mice where the extinction test was performed only on withdrawal day 10. Therefore, there is a possibility that on withdrawal day 10 the nosepokes were lower because mice had undergone the extinction test once already. In our unpublished data where we have used different experiment settings, but have performed extinction tests on withdrawal day 10 only, we have not observed differences on between and within-subject paradigms. Therefore, in this study this may not result in a large difference considering that the effects are rather small. 
There are previous reports that have implemented automated cages to study alcohol drinking behavior. In these elegant studies, that include a social context and minimal human interference, similar alcohol consumption is reported [14, 21, 28-30]. However, these studies have not focused on cue-induced craving after withdrawal. Instead, previous research focuses on a variety of different addiction-like behaviors such as motivation, persistent and compulsive alcohol seeking, as well as on punishment and the intensity of relapse after alcohol withdrawal.

\section{Conclusions}

We established a new model to study cue-induced alcohol craving in the social context in female mice with minimal human interference. Furthermore, we conclude that there is likely a neuroadaptation process that mediates cue-induced drug alcohol craving during the late withdrawal time points. This conclusion is supported by findings that craving (number of nosepokes) in the late withdrawal do not correlate with the amount of consumed alcohol, or the nosepokes on the last training day but is observed only in the case with extended duration of conditioned pairings. Therefore, we conclude that we have established a new tool to study alcohol drinking behavior and craving in female mice.

\section{Acknowledgements}

We thank Roy Wise for interesting discussions and for giving the inspiration to carry out this work. We thank Katrina Albert for proofreading the manuscript. VV is supported by Jane and Aatos Erkko Foundation, Mouse Behavioural Phenotyping Facility is supported by University of Helsinki (HiLIFE) and Biocenter Finland. MK and experiments are supported by Finnish Foundation for Alcohol Studies. MA is supported by Academy of Finland and 3iRegeneration Tekes. 


\section{References}

[1] G.F. Koob, M. Le Moal, Plasticity of reward neurocircuitry and the 'dark side' of drug addiction, Nature neuroscience 8(11) (2005) 1442-4.

[2] W.A. Hunt, L.W. Barnett, L.G. Branch, Relapse rates in addiction programs, J Clin Psychol 27(4) (1971) 455-6.

[3] C.L. Pickens, M. Airavaara, F. Theberge, S. Fanous, B.T. Hope, Y. Shaham, Neurobiology of the incubation of drug craving, Trends in neurosciences 34(8) (2011) 411-20.

[4] G. Edwards, M.M. Gross, Alcohol dependence: provisional description of a clinical syndrome, British medical journal 1(6017) (1976) 1058-61.

[5] C.P. O'Brien, A.R. Childress, A.T. McLellan, Conditioning factors may help to understand and prevent relapse in patients who are recovering from drug dependence, NIDA Res Monogr 106 (1991) 293-312.

[6] H.C. Becker, D. Ron, Animal models of excessive alcohol consumption: recent advances and future challenges, Alcohol 48(3) (2014) 205-8.

[7] C. Sanchis-Segura, R. Spanagel, Behavioural assessment of drug reinforcement and addictive features in rodents: an overview, Addiction biology 11(1) (2006) 2-38.

[8] R.A. Wise, Voluntary ethanol intake in rats following exposure to ethanol on various schedules, Psychopharmacologia 29(3) (1973) 203-10.

[9] J.A. Simms, P. Steensland, B. Medina, K.E. Abernathy, L.J. Chandler, R. Wise, S.E. Bartlett, Intermittent access to $20 \%$ ethanol induces high ethanol consumption in Long-Evans and Wistar rats, Alcoholism, clinical and experimental research 32(10) (2008) 1816-23.

[10] L. Valzelli, The "isolation syndrome" in mice, Psychopharmacologia 31(4) (1973) 305-20.

[11] V. Voikar, A. Polus, E. Vasar, H. Rauvala, Long-term individual housing in C57BL/6J and DBA/2 mice: assessment of behavioral consequences, Genes, brain, and behavior 4(4) (2005) 240-52.

[12] J.C. Crabbe, D. Wahlsten, B.C. Dudek, Genetics of mouse behavior: interactions with laboratory environment, Science 284(5420) (1999) 1670-2.

[13] K. Radwanska, L. Kaczmarek, Characterization of an alcohol addiction-prone phenotype in mice, Addiction biology 17(3) (2012) 601-12.

[14] M. Smutek, M. Turbasa, M. Sikora, M. Piechota, J. Zajdel, R. Przewlocki, J.R. Parkitna, A model of alcohol drinking under an intermittent access schedule using group-housed mice, PloS one 9(5) (2014) e96787.

[15] M. Koskela, S. Back, V. Voikar, C.T. Richie, A. Domanskyi, B.K. Harvey, M. Airavaara, Update of neurotrophic factors in neurobiology of addiction and future directions, Neurobiology of disease 97(Pt B) (2017) 189-200.

[16] S. Krackow, E. Vannoni, A. Codita, A.H. Mohammed, F. Cirulli, I. Branchi, E. Alleva, A. Reichelt, A. Willuweit, V. Voikar, G. Colacicco, D.P. Wolfer, J.U. Buschmann, K. Safi, H.P. Lipp, Consistent behavioral phenotype differences between inbred mouse strains in the IntelliCage, Genes, brain, and behavior 9(7) (2010) 722-31.

[17] V. Voikar, G. Colacicco, O. Gruber, E. Vannoni, H.P. Lipp, D.P. Wolfer, Conditioned response suppression in the IntelliCage: assessment of mouse strain differences and effects of hippocampal and striatal lesions on acquisition and retention of memory, Behavioural brain research 213(2) (2010) 304-12.

[18] M. Heilig, D.H. Epstein, M.A. Nader, Y. Shaham, Time to connect: bringing social context into addiction neuroscience, Nature reviews. Neuroscience 17(9) (2016) 592-9.

[19] E.M. Meyer, V. Long, M.S. Fanselow, I. Spigelman, Stress increases voluntary alcohol intake, but does not alter established drinking habits in a rat model of posttraumatic stress disorder, Alcoholism, clinical and experimental research 37(4) (2013) 566-74.

[20] E.J. Chesler, S.G. Wilson, W.R. Lariviere, S.L. Rodriguez-Zas, J.S. Mogil, Influences of laboratory environment on behavior, Nature neuroscience 5(11) (2002) 1101-2.

[21] J.Y. Holgate, H. Garcia, S. Chatterjee, S.E. Bartlett, Social and environmental enrichment has different effects on ethanol and sucrose consumption in mice, Brain Behav 7(8) (2017) e00767. 
[22] J.W. Grimm, B.T. Hope, R.A. Wise, Y. Shaham, Neuroadaptation. Incubation of cocaine craving after withdrawal, Nature 412(6843) (2001) 141-2.

[23] U. Shalev, M. Morales, B. Hope, J. Yap, Y. Shaham, Time-dependent changes in extinction behavior and stress-induced reinstatement of drug seeking following withdrawal from heroin in rats, Psychopharmacology (Berl) 156(1) (2001) 98-107.

[24] J.D. Shepard, J.M. Bossert, S.Y. Liu, Y. Shaham, The anxiogenic drug yohimbine reinstates methamphetamine seeking in a rat model of drug relapse, Biol Psychiatry 55(11) (2004) 1082-9.

[25] A. Abdolahi, G. Acosta, F.J. Breslin, S.E. Hemby, W.J. Lynch, Incubation of nicotine seeking is associated with enhanced protein kinase A-regulated signaling of dopamine- and cAMP-regulated phosphoprotein of $32 \mathrm{kDa}$ in the insular cortex, Eur J Neurosci 31(4) (2010) 733-41.

[26] J.W. Grimm, Y. Shaham, B.T. Hope, Effect of cocaine and sucrose withdrawal period on extinction behavior, cue-induced reinstatement, and protein levels of the dopamine transporter and tyrosine hydroxylase in limbic and cortical areas in rats, Behav Pharmacol 13(5-6) (2002) 379-88.

[27] P. Bienkowski, A. Rogowski, A. Korkosz, P. Mierzejewski, K. Radwanska, L. Kaczmarek, A. BoguckaBonikowska, W. Kostowski, Time-dependent changes in alcohol-seeking behaviour during abstinence, Eur Neuropsychopharmacol 14(5) (2004) 355-60.

[28] Z. Mijakowska, K. Lukasiewicz, M. Ziolkowska, M. Lipinski, A. Trabczynska, Z. Matuszek, S. Leski, K. Radwanska, Autophosphorylation of alpha isoform of calcium/calmodulin-dependent kinase II regulates alcohol addiction-related behaviors, Addict Biol (2015).

[29] J.R. Parkitna, M. Sikora, S. Golda, K. Golembiowska, B. Bystrowska, D. Engblom, A. Bilbao, R. Przewlocki, Novelty-Seeking Behaviors and the Escalation of Alcohol Drinking After Abstinence in Mice Are Controlled by Metabotropic Glutamate Receptor 5 on Neurons Expressing Dopamine D1 Receptors, Biol Psychiatry 73 (2013) 263-270.

[30] K. Radwanska, L. Kaczmarek, Characterization of an alcohol addiction-prone phenotype in mice, Addict Biol 17 (2012) 601-612. 


\section{Figure legends}

Figure 1. Experimental design. A. Schematic representation of the automated cage used in the studies. The apparatus consists of four recording chambers that fit into the corners of the housing cage. Access into the chambers is provided via a tubular antenna (50 $\mathrm{mm}$ outer and $30 \mathrm{~mm}$ inner diameter) reading the transponder codes. Each of the chambers are equipped with an alcohol or water bottle. Access to the bottle is provided with a proximity sensor and each opening of $13 \mathrm{~mm}$ diameter (one on the left, one on the right) gives access to bottle nipples. The corners are marked in Roman numerals. Sides with conditional stimulus CS+ and without CS- are colored in grey and white, respectively. B. Picture of conditional corner. Green light is used as the conditional stimulus (CS+ side). White discs are doors that hide the bottle spout. Nosepoke opens the door. C. Schematic representation of the schedule for intermittent access to alcohol in the automated cage (Procedure I). On the scheme w - water. D. Schematic representation of the schedule for intermittent access to alcohol in the standard home cage (Procedure II). To facilitate the reader, red lines in Fig. 1C and Fig. 1D represent the time spent in the automated cage 
A

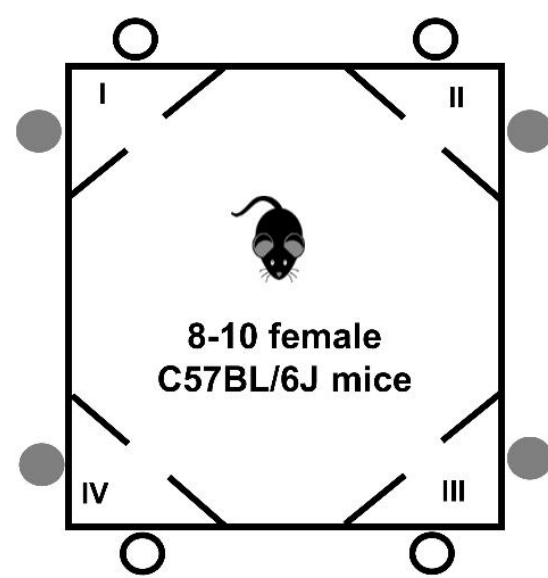

B
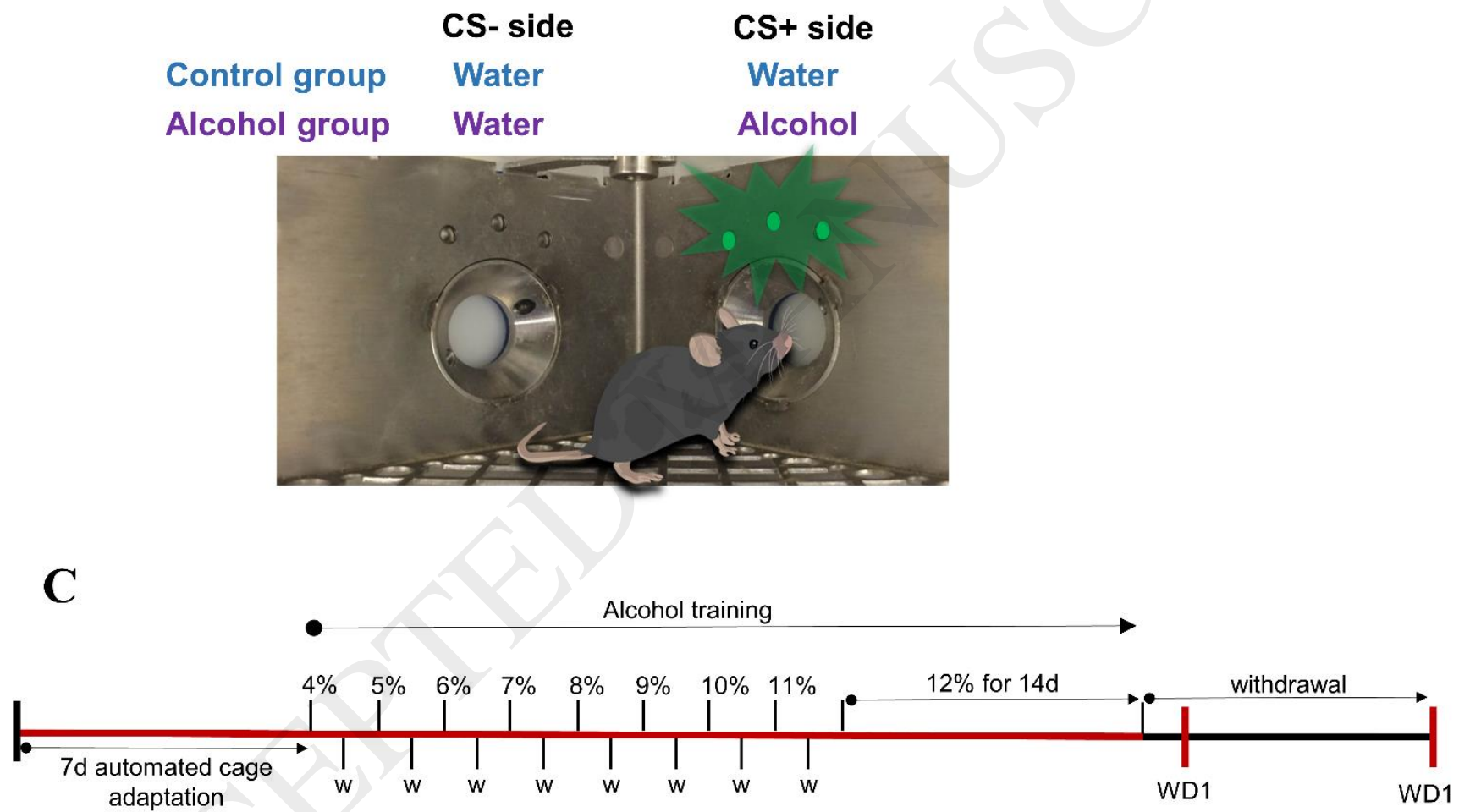

\section{D}

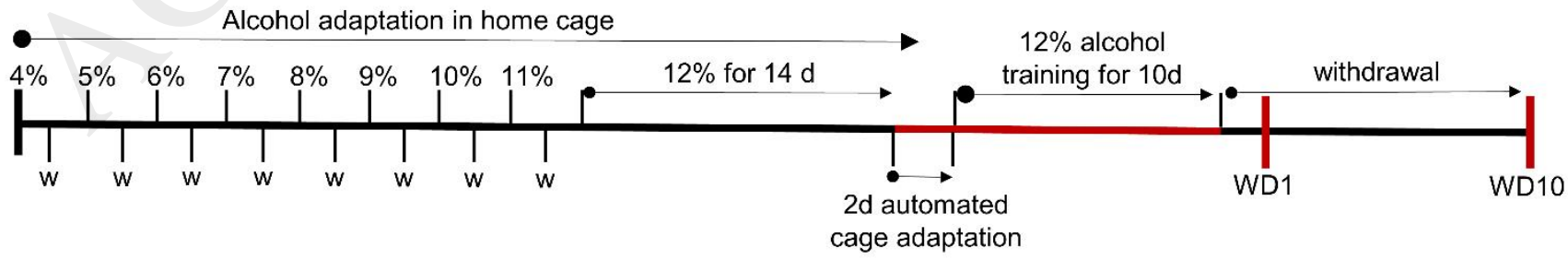


Figure 2. Behavioral activity during intermittent alcohol access in the automated cage on days when alcohol was available. The mice were combined in groups of 10 and 11 mice per cage for intermittent Alcohol group and 10 mice per cage for Water group. A. Number of visits to conditioned corner. B. Number of nosepokes to conditional side (CS+) of conditioned corner. C. Number of nosepokes to non-conditional side (CS-) of conditioned corner. D. Number of licks to conditional side (CS+) of conditioned corner. E. Number of licks to non-conditional side (CS-) of conditioned corner. All means are presented with their standard errors $( \pm$ SEM). 
A

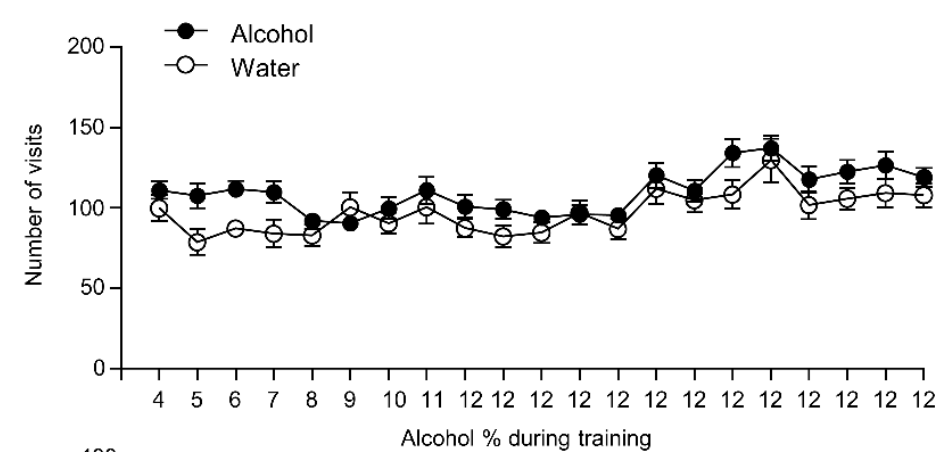

B

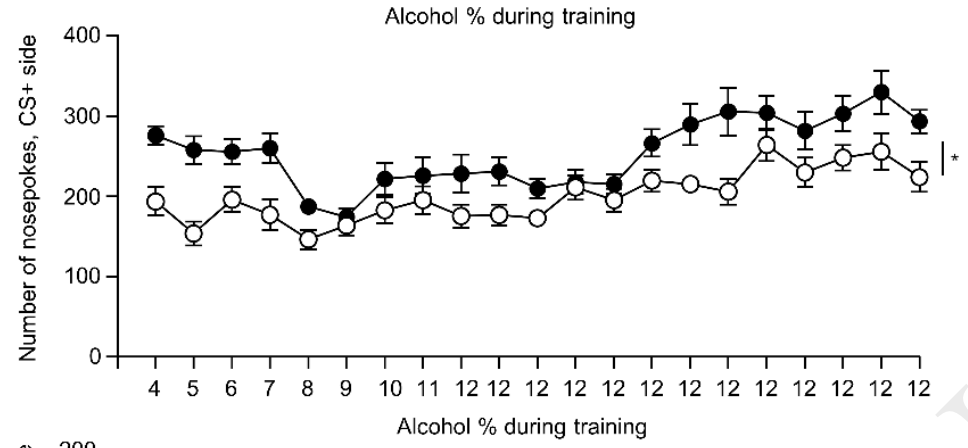

C

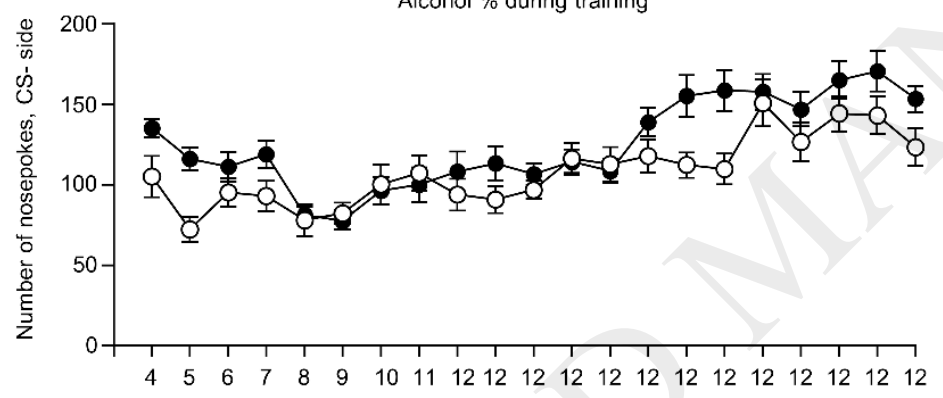

D

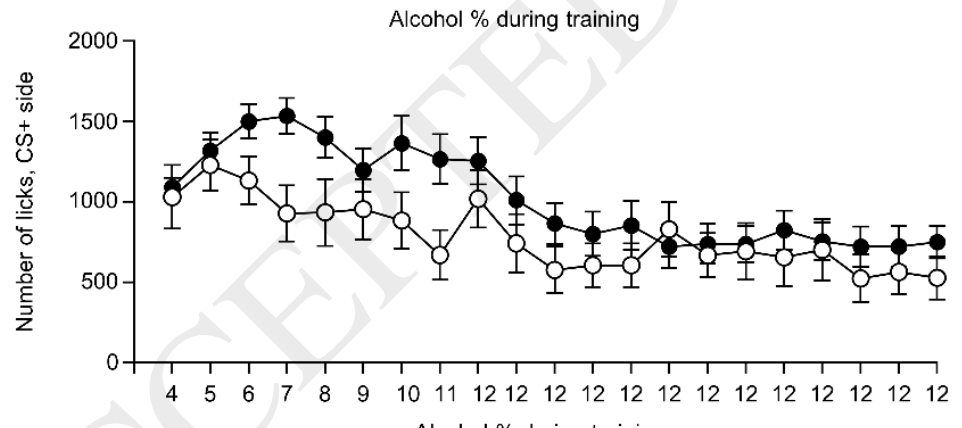

E

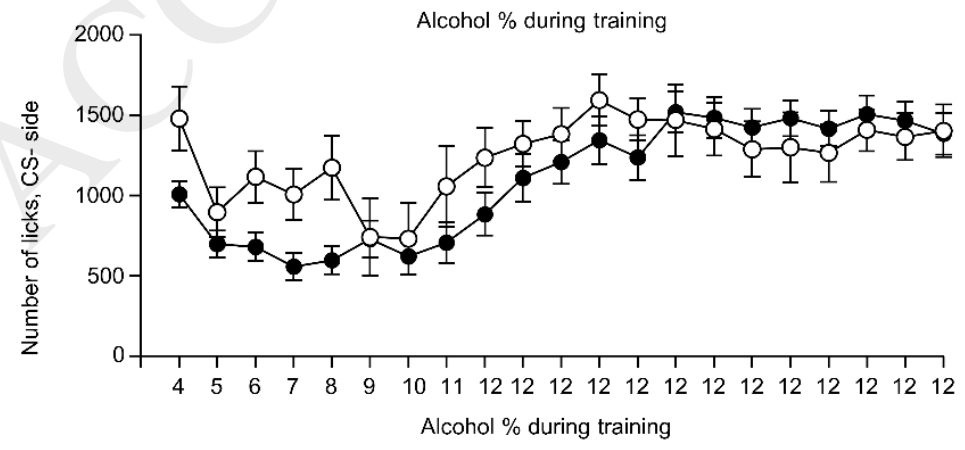


Figure 3. Visit duration during training when alcohol was available and consumed ethanol. A. Time spent inthe conditioned corner. B. The ethanol dose that mice consumed during alcohol training days was estimated as $\mathrm{g} / \mathrm{kg} / 24 \mathrm{~h}$. All means are presented with their standard errors $( \pm \mathrm{SEM})$.

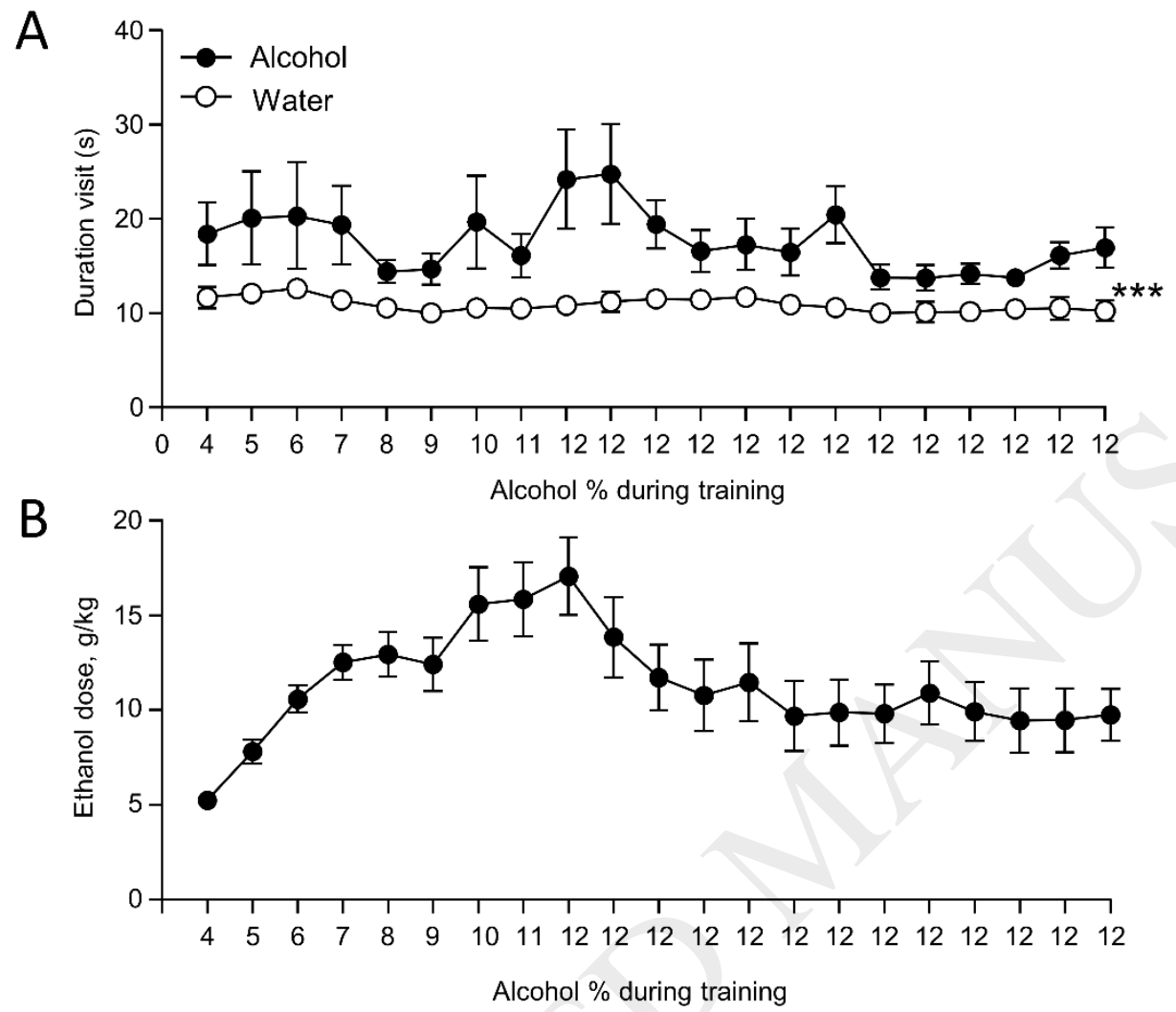

Figure 4. Behavioral activity during extinction tests after intermittent alcohol access in the automated cage. A. Number of visits to conditioned corner on withdrawal day 1 (WD1) and 10 (WD10). B. Number of nosepokes to conditional sides CS+ and CS- of conditioned corner on WD1 and WD10. C. Number of licks to conditional sides CS+ and CS- of conditioned corner on WD1 and WD10. D. Visit duration in conditioned corner on WD1 and WD10. All means are presented with their standard errors $( \pm \mathrm{SEM})$. 


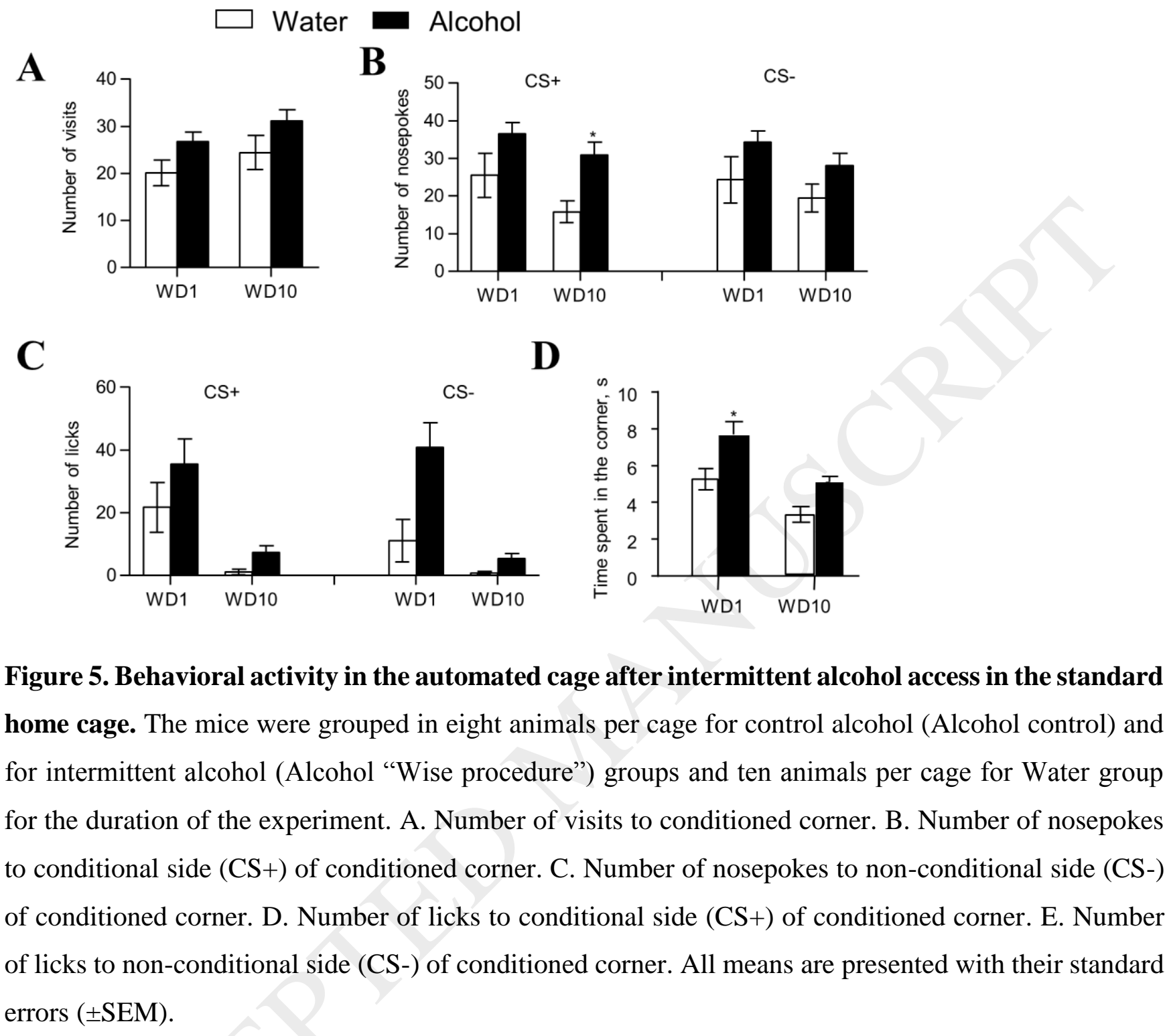



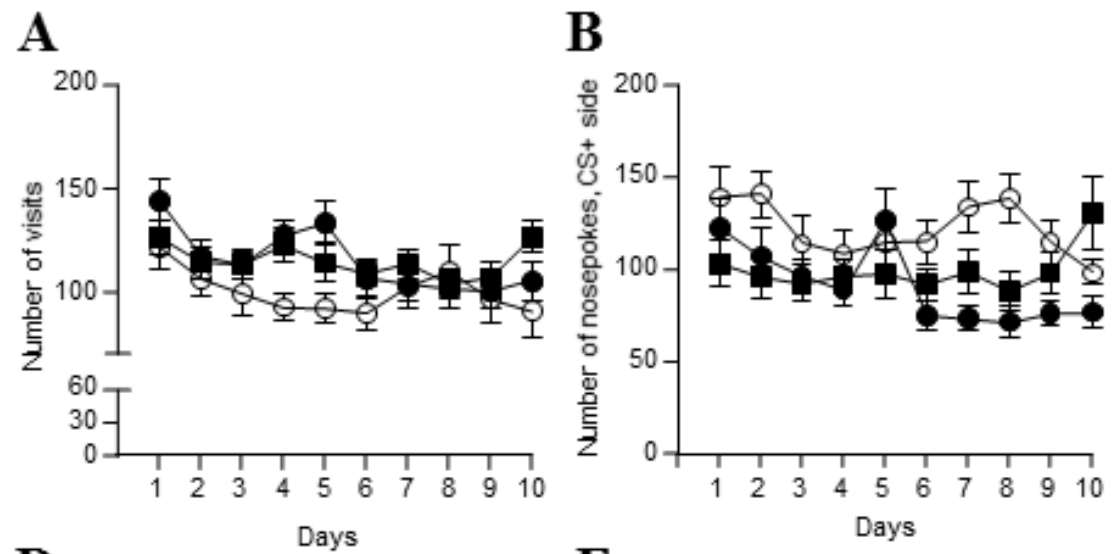

C

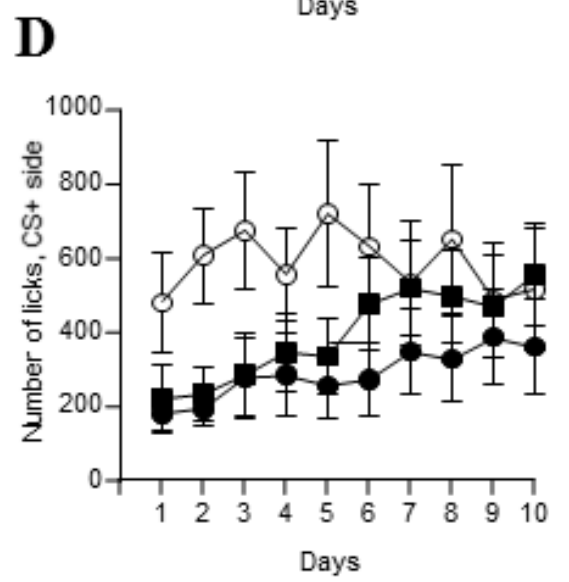

$\mathbf{E}$
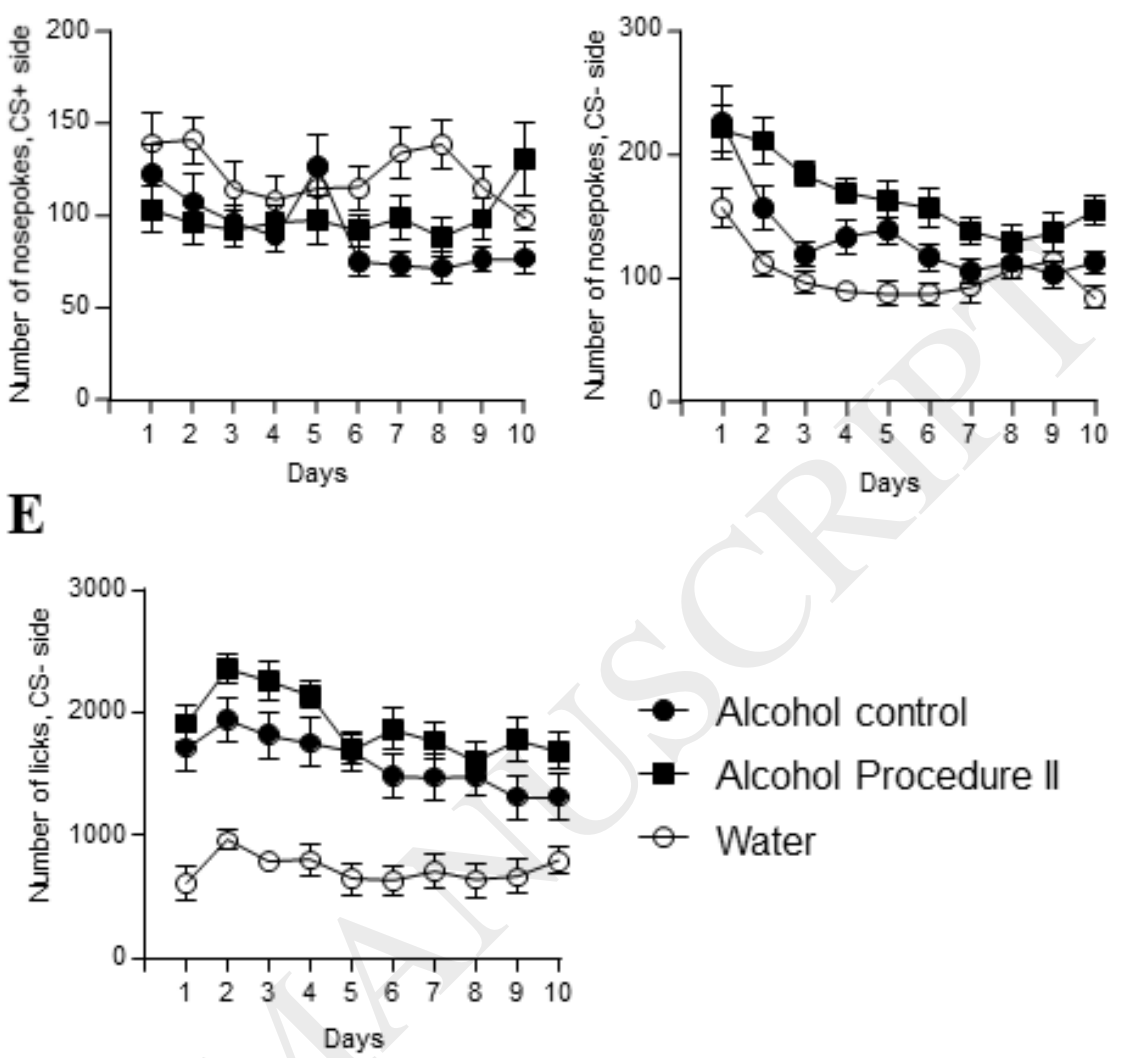

Figure 6. Consumed ethanol dose in the Alcohol control and Alcohol "Wise procedure" groups. The ethanol dose that mice consumed during alcohol training days in automated cage was estimated as $\mathrm{g} / \mathrm{kg} / 24 \mathrm{~h}$. All means are presented with their standard errors ( \pm SEM).

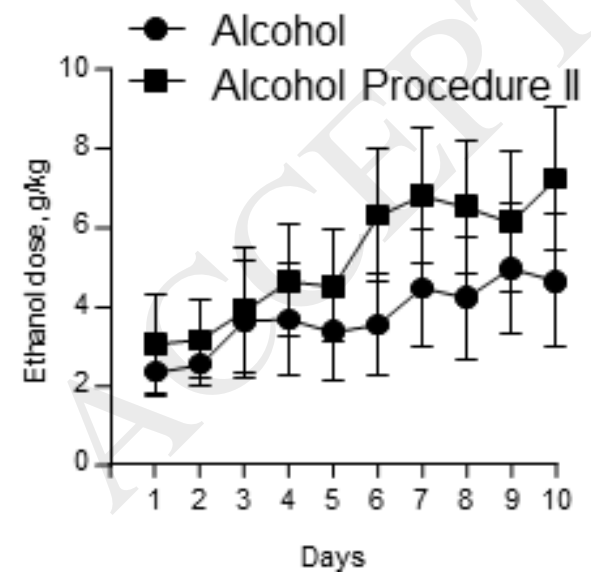

Figure 7. Behavioral activity of Alcohol control and Alcohol "Wise procedure" groups during extinction tests after training in the automated cage. A. Number of visits to conditioned corner on withdrawal day 1 (WD1) and 10 (WD10). B. Number of nosepokes to conditional sides CS+ and CS- of 
conditioned corner on WD1 and WD10. C. Number of licks to conditional sides CS+ and CS- of conditioned corner on WD1 and WD10. D. Visit duration in conditioned corner on WD1 and WD10. All means are presented with their standard errors $( \pm$ SEM).

A

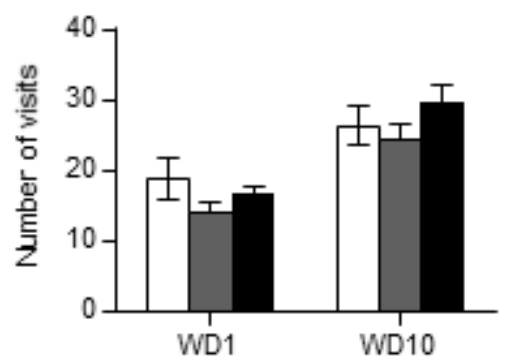

C

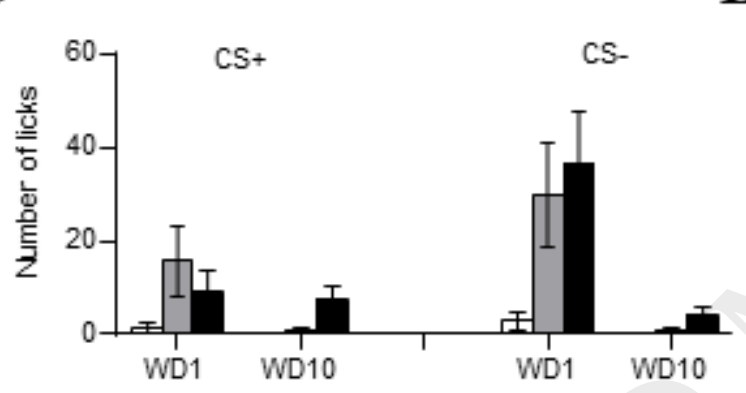

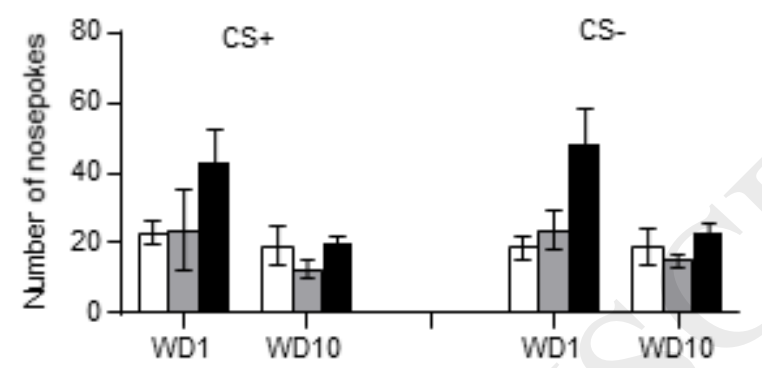

D

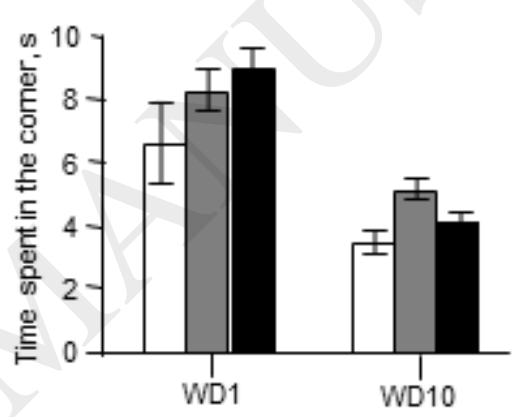

Figure 8. The Pearson correlation coefficient was calculated to evaluate a link between number of nosepokes to conditional CS+ side on WD1 and WD10 and consumed alcohol dose or number of nosepokes on the last day of the training period. A. No correlation was observed between consumed alcohol dose on the last day of training and number of nosepokes to conditional CS+ side on WD1 ( $\mathrm{r}=$ $0.05, \mathrm{p}=0.34)$. B. No correlation was observed between consumed alcohol dose on the last day of training and number of nosepokes to conditional CS+ side on WD10 $(r=0.01, p=0.64)$. C. The number of nosepokes on the last day of training positively correlated with the number of nosepokes on WD1 ( $\mathrm{r}=$ $0.28, \mathrm{p}=0.01$ ). D. No correlation was observed between the number of nosepokes on the last day of training and the number of nosepokes on WD10 $(r=0.07, p=0.27)$. 

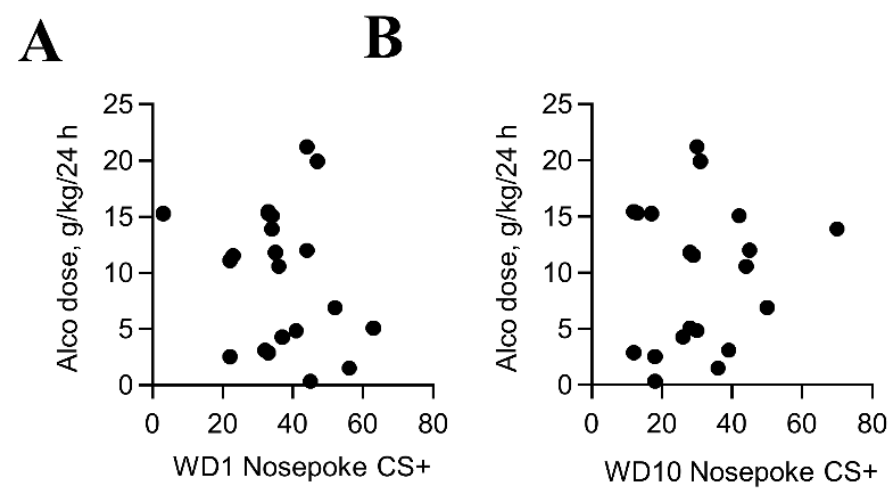

C

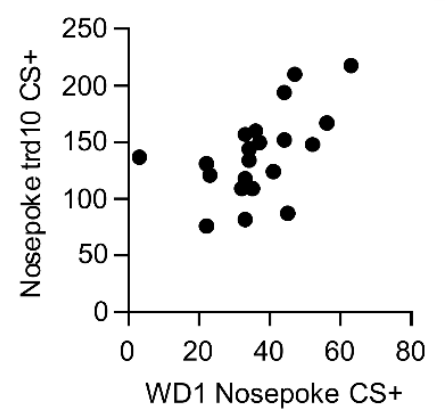

D

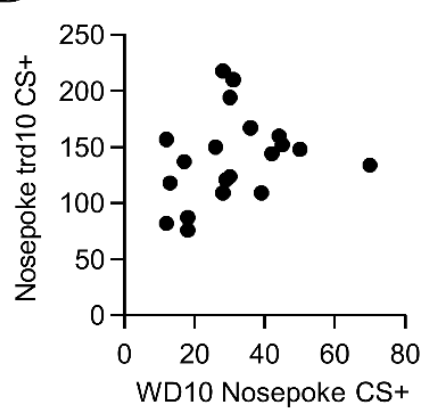

